\title{
Avaliação do comportamento de consumidores no processo de decisão de compra no M-Commerce e no E-Commerce
}

\section{Alternative Title: Evaluation of Consumer Shopping Behavior in M-Commerce and E-Commerce}

\author{
Felipe Lemos \\ Pontifícia Universidade Católica de Minas Gerais \\ Contagem - Minas Gerais \\ CEP: 32010-025 \\ felipe.lemos.almeida@gmail.com
}

\author{
Luís Fabrício Góes \\ Pontifícia Universidade Católica de Minas Gerais \\ Contagem - Minas Gerais \\ CEP: 32010-025 \\ Ifwgoes@yahoo.com.br
}

\begin{abstract}
RESUMO
Este artigo avalia o comportamento de consumidores que efetuam compras através do Comércio Eletrônico utilizando uma plataforma Web e outra Mobile. Pretende-se analisar o motivo pelo qual consumidores preferem concluí-las através de um computador, já que o mercado de dispositivos móveis se encontra em alta.
\end{abstract}

\section{Palavras-Chave}

Comércio Eletrônico, Compartamento do Consumidor, Mobile Commerce, Compras, Internet, Loja Virtual

\begin{abstract}
This paper intends to anlyze why e-commerce is more popular than mobile commerce among internet users, despite the growth of mobile market. Through survey research carried out among 130 users, it was possible to infer that people use mobile devices along the day and prefer using computers than mobile devices in all phases of their purchases. The possible reasons of that behavior is related to safety conditions of $\mathrm{m}$-commerce and errors that occur on eletronic transactions. Mobile devices are used auxialiry tool to check available products on market and to follow the track of requests already done.
\end{abstract}

\section{Categories and Subject Descriptors}

K.4.4 [Electronic Commerce]: Miscellaneous; J.4 [Social and Behaviorial Sciences]: Economics

\section{General Terms}

Verification

Permission to make digital or hard copies of all or part of this work for personal or classroom use is granted without fee provided that copies are not made or distributed for profit or commercial advantage and that copies bear this notice and the full citation on the first page. To copy otherwise, to republish, to post on servers or to redistribute to lists, requires prior specific permission and/or a fee.

SBSI 2015, May 26th-29th, 2015, Goiânia, Goiás, Brazil

Copyright SBC 2015.

\section{Keywords}

m-commerce, e-commerce, consumer behavior, online store, online shop

\section{INTRODUÇÃO}

O Brasil, atualmente, é um dos países mais promissores quando o assunto gira em torno do Comércio Eletrônico. Isso ocorre devido às inovações no setor de Tecnologia da Informação e Comunicação e o aumento significativo de pessoas com acesso a Internet no país. Pesquisas revelam que no ano de 2013 foram faturados 28 bilhões com Comércio Eletrônico, cerca de $25 \%$ a mais que no ano anterior [8]. Diante de um cenário tão promissor, empresas estão utilizando a Internet para oferecer variados tipos de serviços. Dentre eles, o E-Commerce vem se destacando por apresentar, nos últimos anos, alto índice de crescimento.

Uma nova tendência que também aparece no mercado brasileiro, chamando atenção das empresas, é o $M$-Commerce, Comércio Eletrônico para dispositivos móveis. O surgimento desse tipo de serviço se deu em razão do crescimento nas vendas de smartphones, que, por sua vez, foi um dos fatores que impulsionaram o índice de pessoas com acesso à Internet no Brasil [23].

Considerando o exposto anteriormente, as operadoras de telefonia foram levadas a evoluir o serviço de Internet e melhorar sua infraestrutura para suportar a referida demanda. Isso ocasionou durante os últimos anos a evolução da Internet de $2 \mathrm{G}$, para $3 \mathrm{G}$, e, atualmente para $4 \mathrm{G}$. Assim, com o aumento da velocidade da Internet e a praticidade em acessá-la, vêm colaborando para o desenvolvimento do $M$ Commerce, juntamente com número de consumidores para essa plataforma. As corporações, visando explorar esse mercado, começam a migrar suas lojas para essa linha. Igualmente, dados mostram a evolução nas vendas através do $M$-Commerce, chegando a $4 \%$ do total arrecadado com Comércio Eletrônico no ano de 2013 [8].

No entanto, esse percentual está abaixo do esperado, levando em consideração a quantidade de aparelhos conectados à Internet, que no mesmo ano foram registrados 96,1 milhões de acessos através de celulares, incluindo os smartphones [23].

Diante da situação, é possível afirmar que as condições são favoráveis para expansão do $M$-Commerce no Brasil, porém, 
aproximadamente $86 \%$ das pessoas utilizam os smartphones apenas para buscar informações, preferindo, contudo, finalizar a compra através do E-Commerce ou na própria loja física [12].

Sendo assim, o principal objetivo deste trabalho é analisar o comportamento de consumidores no $M$-Commerce, fazendo a comparação com os que utilizam E-Commerce e desta forma será possível entender porque estes não finalizam suas compras pelo próprio dispositivo móvel.

A estrutura do artigo é dada pela seguinte organização: na seção 2 é feita uma abordagem sobre o E-Commerce e seus conceitos, e na sequência, é apresentado o $M$-Commerce na seção 3 juntamente com sua atuação no páis 3.1. Na seção 4 é apresentado o comportamento do consumidor e as etapas do processo decisório de compra. A seção 5 contempla os trabalhos relacionados e na seção 6 é apresenta a metodologia. Os resultados da pesquisa são exibidos na seção 7 e para finalizar a conclusão e os trabalhos futuros aparecem na seção 8 .

\section{E-COMMERCE}

$\mathrm{Na}$ atualidade, existem diferentes conceitos sobre o Comércio Eletrônico, entretanto, no presente trabalho, iremos abordar sua definição como qualquer tipo de transação comercial efetuada por empresas de forma eletrônica, a fim de fornecer algum tipo de serviço/produto [1]. Segundo Carvalho [5], "essa forma de negociar - o Comércio Eletrônico engloba um conjunto de atividades que vai além da compra e venda de produtos e/ou serviços, mas que inclui pesquisa de mercado, oferta e promoção de produtos, suporte a clientes, dentre outras".

Existem três modelos principais de e-business (negócios efetuados por meio eletrônico), de acordo com conceitos elaborados, pelos autores Deitel e Obrien[7, 18]; então, podemos citar: B2B (Business-to-Business), C2C (Consumerto-Consumer) e B2C (Business-to-Consumer). No primeiro caso, B2B, é a negociação eletrônica envolvendo empresas, ao passo que o $\mathrm{C} 2 \mathrm{C}$ consiste na transação on-line realizada entre pessoas físicas; em relação ao $\mathrm{B} 2 \mathrm{C}$, empresa para consumidor, será o modelo comtemplado neste trabalho devido a um dos seus objetivos, que é o estudo do comportamento de usuários nas compras realizadas através de uma loja virtual.

\section{M-COMMERCE}

Conforme as considerações sobre E-Commerce, antes de se fazer uma abordagem sobre o $M$-commerce, é necessário dispor sobre o surgimento deste serviço, para que seja entendido porquê o mesmo, nos dias atuais, já é considerado a tecnologia que poderá substituir o E-Commerce.

O M-Commerce, Comércio Eletrônico para dispositivos móveis, teve início quando os celulares, por volta do ano 1990, começaram a ter acesso à Internet através da rede 1G, tecnologia que já existia desde os anos 80. Entretanto, muitos problemas eram enfrentados pelos usuários, que quase nunca conseguiam acessar a rede, devido a vários fatores, tais como: dificuldade de acesso, baixa velocidade (9.6kbps), e aparelhos que não ofereciam esse tipo conexão. Para suprir as limitações da Internet de primeira geração, as operadoras foram levadas a evoluir sua infraestrutura, sendo que na mesma década de 90, surgiu a segunda geração, a Internet $2 \mathrm{G}$, essa por sua vez já era digital, possuía mais segurança e uma velocidade de $20 \mathrm{kbps}$ a $50 \mathrm{kbps}$ [16].

Antes de dar continuidade na evolução da Internet móvel, é importante salientar que, em paralelo os celulares também estavam em constante evolução e, que tudo isso somente estava acontecendo porque a procura estava sendo muito maior do que a oferta, contudo a capacidade dos aparelhos era muito restrita e serviam somente para receber/fazer ligações, enviar mensagens e realizar algumas operações básicas. Quando esses foram adquirindo novos hardwares, consequentemente, adquirindo novas funções e utilidades, como jogos, possibilidade de escutar música, tirar fotos, entre outras, os usuários sentiram a necessidade de acesso à Internet, para comprar ou fazer download destes itens. Com evolução da Internet, juntamente com aumento de acessos proporcionados pelos celulares, empresas começaram a disponibilizar serviços/produtos para serem consumidos através deste novo meio.

Com aumento considerável de usuários, a Internet Móvel $2 \mathrm{G}$ evoluiu para $2,5 \mathrm{G}$ e posteriormente para $2,75 \mathrm{G}$, essa já possuía velocidade de acesso aproximadamente de 400kpbs, onde já era possível fazer download de jogos, músicas e comunicar com pessoas, de forma mais eficiente. As companhias Google e PayPal foram fundadas, por volta de 1998, e durante os 4 anos subsequentes Hotmail, Netscape, Yahoo e Amazon, ou seja, no ano de 2000, a Internet já funcionava como um comércio, onde consumidores buscavam, eletronicamente, produtos e faziam transações [14].

Outro fator que impulsionou o aumento de usuários na Internet através de celulares, juntamente com evolução dos mesmos para se tornarem smartphones, foram as redes sociais. Atualmente a Internet se encontra na sua quarta geração $(4 \mathrm{G})$, entretanto a maioria dos usuários ainda está na terceira geração (3G), tendo em vista que cerca de $80 \%$ utiliza está conexão.

É possível concluir que, assim como o E-Commerce, o $M$ commerce possui fatores semelhantes que fizeram com que esse serviço pudesse ganhar força no mercado de Comércio Eletrônico, dentre eles, podemos citar: evolução da Internet móvel e evolução dos celulares.

\subsection{M-Commerce no Brasil}

O $M$-commerce vem aumentando seu percentual de vendas no Brasil, entretanto, ainda avança a passos curtos. Para Migliorini[16], alguns dos fatores a serem considerados consistem no fato das empresas não investirem neste serviço, pois, ainda trata-se de uma tecnologia inovadora. O autor cita também que a falta de interesse por parte dos varejistas se deve à segurança do consumidor. A falta de padrões em celulares, navegadores de Internet e a falta de investimento na estrutura de rede por parte das operadoras, também contribuem para que as organizações não invistam no M-commerce.

Já o consumidor, centro das atenções neste trabalho, também enfrenta muitas dificuldades ao usufruir deste serviço, dentre elas as restrições de hardware (tamanho da tela), acesso a rede Internet (muito lenta na maioria das vezes), adaptação (usuários não executam as mesmas tarefas que conseguiriam usando o computador), dificuldade (habilidade na execução da compra), todos esses são fatores que influenciam na hora da compra, principalmente através do celular [16]. Mas, apesar destes fatores, os consumidores, possuem uma boa perspectiva em relação a este mercado, uma vez que a comodidade é um fator de peso, que traz benefícios 
para os mesmos, já que eles conseguem efetuar uma compra, ou realizar um pedido, em qualquer lugar e a qualquer hora sem precisa ligar o computador.

As vendas no Brasil chegaram a $4 \%$ do total arrecado com Comércio Eletrônico em 2013, sendo que no ano anterior foi de aproximadamente $2 \%$. Um progresso considerado bom por especialistas da área, que ainda afirmam que até 2018, o $M$-Commerce já vai ter superado o E-Commerce.

\section{COMPORTAMENTO DO CONSUMIDOR}

Entender o comportamento do consumidor é de extrema importância para saber como ele fundamenta suas decisões na hora de efetuar uma compra. Segundo o modelo apresentado pelos autores Kotler e Keller[13], este processo é constituído por cinco etapas: reconhecimento das necessidades, procura de informação, avaliação das alternativas, decisão de compra e avaliação pós-compra. Como citado anteriormente, este estudo faz-se bastante necessário principalmente quando falamos de vendas online, pois o vendedor não tem um contato direto com o comprador. Com isso, é necessário que empresas que praticam vendas online entendam como serão as atitudes tomadas pelos e-consumidores, para que desta forma, as mesmas possam construir e/ou aprimorar suas estratégias de marketing.

O Kotler e Keller[13] modelo apontado anteriormente é utilizado por vários autores quando há necessidade de se realizar um estudo sobre o comportamento do consumidor na hora da compra, pois as etapas contidas nele demonstram todo o processo decisão, desde o início quando surge a necessidade até o final, que é o pós-compra. Neste trabalho foi utilizado este mesmo modelo nas plataformas a serem estudadas - E-Commerce, $M$-commerce - apresentando também conceitos de alguns autores sobre as etapas envolvidas no processo decisório.

\subsection{Reconhecimento das necessidades}

Esta primeira etapa é definida por Blackwell[9] como o início do processo de tomada de decisão, e esta pode ser causada por fatores como: mudança de circunstâncias, aquisição de produtos, consumo de produto, diferenças individuais e marketing.

Para Kotler[13], a necessidade para efetuar uma compra, pode surgir através de estímulos internos ou externos. No primeiro caso, são as necessidades normais (fome, sede, sexo), no momento que se tornam conscientes acabam se tornando um impulso, e, para o segundo caso, os desejos são causados por fatores externos, ou seja, algo que irá chamar atenção do consumidor e influenciá-lo a comprar.

Levando em consideração os conceitos apresentados anteriormente, empresas que trabalham com Comércio Eletrônico necessitam de informações sobre o que pode estimular uma compra online, pois o processo de decisão se inicia neste estágio, ou seja, vem da necessidade em adquirir/comprar algo, perceber como isso ocorre é um fator fundamental para o progresso no modelo B2C.

\subsection{Procura de Informação}

Após o surgimento da necessidade, ocorre o segundo estágio que é a busca por informações. Esta etapa consiste em realizar uma análise das informações que estão armazenadas na memória, bem como encontrá-las através de uma pesquisa [4].

Kotler e Keller[13] definem a busca de informações a partir de níveis de interesse. Eles classificam estes em dois níveis; quando a busca é moderada é definido como atenção elevada, por outro lado, quando a procura é intensa, classificase como busca ativa de informações. Citam também, que as fontes de informações estão dividas em quatro grupos:

- Fontes pessoais: Família, amigos, conhecidos.

- Fontes Comerciais: Propaganda, vendedores, mostruários.

- Fontes públicas: Internet.

- Fontes Experimentais: Uso do produto [13].

Para Costa[6], o mercado disponibiliza todas as informações específicas dos produtos para que os consumidores possam consultá-las antes de efetuar uma compra, este processo é chamado de pesquisa pré-compra, ainda segundo o autor, o outro processo é denominado de pesquisa contínua, esse por sua vez ocorre quando o consumidor faz pesquisas constantes para se manter atualizado.

$\mathrm{Na}$ etapa anterior, o consumidor percebe a necessidade em adquirir algo, mas é nesta que ele irá buscar informações sobre o que deseja comprar, para confirmar se o produto será capaz de suprir tal necessidade. Esta tarefa é de extrema importância quando a compra será realizada através do Comércio Eletrônico, pois em ambos, a descrição, as características e as informações técnicas do produto, devem estar bem descritas. De acordo com pesquisa realizada pela HiMidia[11], a Internet é uma grande influenciadora na hora de decidir a compra. Ainda acrescenta em sua pesquisa que: $77 \%$ dos entrevistados procuram informações de produtos e serviços na Internet.

É possível destacar vantagens e desvantagens entre a busca de informações realizada através do computador e a realizada pelo celular. Um estudo, "Our Mobile Planet" encomendado pela Google e realizado pelas empresas MediaCT e TNS Intratest, revela que $46 \%$ dos usuários que utilizaram o celular para realizar uma pesquisa, acabaram não efetuando a compra e $27 \%$ finalizaram diretamente no smartphone, acrescenta também que, $45 \%$ dos usuários finalizaram a compra em um computador e outros $30 \%$ preferiram finalizar a compra em uma loja física[20].

Referente à pesquisa, é possível destacar que a possibilidade de acessar o $M$-commerce a qualquer hora e em qualquer lugar, dá a esta uma vantagem sobre seu concorrente ( E-Commerce). Entretanto, o mesmo pode apresentar problemas quanto à navegabilidade, agilidade e usabilidade.

\subsection{Avaliação das alternativas}

Após obter informações necessárias sobre o que deseja, o consumidor, a partir de uma análise prévia, irá escolher onde irá de fato efetuar sua compra. Para Blackwell[4], existem alguns critérios que são levados em consideração na hora da compra, como: preço, marca, país de origem, etc. Já Silva[22] complementa dizendo que é nesta fase em que se avaliam os riscos da compra, e somente se o usuário não encontrar nada que o atrapalhe, o mesmo dará prosseguimento no processo.

Blackwell[4] afirma que os consumidores devem levantar um conjunto de considerações a serem feitas, quais fatores devem ser determinantes para compra, ou então escolher através do seu próprio conhecimento. Angelo e Silvera[2] 
também ressaltam que os mesmos devem efetuar comparações entre as alternativas capazes de solucionar tal necessidade. É importante ressaltar que neste estágio, o consumidor irá definir onde comprar e o que comprar, de acordo com as necessidades consideradas de importância [6].

Segundo Kotler[13], o consumidor avalia um produto por sua quantidade de atributos, e cada um sua capacidade de proporcionar benefícios, aos quais possa suprir suas necessidades. Complementa dizendo que os consumidores prestarão mais atenção aos atributos que são capazes de atender o que está sendo procurado.

Ao chegar nesta etapa, o mesmo pode decidir comprar através de uma loja virtual ou até mesmo em uma loja física, isso vai depender dos fatores que este considerar relevantes para tomar sua decisão. Angelo e Silvera[3] ressaltam alguns fatores que levará o consumidor a escolher a loja virtual, como por exemplo: conveniência, economia de tempo, preços mais baratos, variedade de produtos oferecida, acesso 24 horas, mais informações sobre os produtos, personalização, acesso a produtos de outros lugares (estados, países). Em contrapartida, existem fatores que influenciam para escolha da loja física, como: entrega, segurança, contato direto com produto e com vendedor.

\subsection{Decisão de Compra}

Após obter todas as informações necessárias e avaliar as alternativas, eis que nessa etapa o consumidor irá efetuar a compra. Este processo se inicia quando o consumidor visita a loja (virtual ou física), escolhe o produto e efetua o pagamento. Durante esse procedimento, podem ocorrer vários fatores impeditivos para que este seja completado com sucesso. Blackwell[4], afirma que os consumidores podem mudar de opinião e comprar algo totalmente diferente do que era previsto, eles também podem mudá-la devido a ocasiões econômicas, promoções, falta do produto ou até mesmo por falta de motivação.

No Comércio Eletrônico, os fatores aumentam por causa das questões técnicas, como: tempo de resposta do site, interface, usabilidade, erros inesperados, velocidade da Internet, entre outros. Caso alguns dos problemas citados anteriormente ocorram, o usuário irá desistir da compra, ou irá procurar outra loja para finalizá-la. Isso, ocorre devido aos e-consumidores serem mais impacientes quando estão realizando suas compras no varejo virtual. Martins[15] cita que a falta de informações sobre produtos e um serviço de má qualidade podem fazer o consumidor desistir da compra

Uma compra bem sucedida pode fazer com que o cliente se torne um "cliente fixo", ou fidelizado, e esse é objetivo de toda organização. Quando este passa por uma compra, e fica satisfeito, o mesmo irá armazenar em sua memória determinada loja, isso faz com que, em necessidades futuras, o cliente volte a procurá-la. Caso aconteça o contrário, de encontrar muitos problemas, além de não comprar, irá reclamar de forma pública (amigos, familiares, Internet, etc), e isso pode trazer grandes prejuízos para a empresa.

\subsection{Avaliação pós-compra}

Costa[6] ressalta que um consumidor só ficará satisfeito/ insatisfeito após ter consumido(usado) um produto/serviço que foi adquirido.

Muitas lojas virtuais possibilitam que os consumidores postem comentários e façam avaliação de um determinado produto que foi ou será adquirido. Principalmente após o uso, e a experiência adquirida, o consumidor irá compartilhar sua opinião tanto no site em que efetuou a compra, quanto na rede de modo geral.

\section{TRABALHOS RELACIONADOS}

Fell, Rodrigues e Vieira[21] fazem uma avaliação da experiência de compra no E-Commerce a partir da taxonomia da usabilidade. Ainda segundo estes, a construção de uma loja virtual deve ser feita através da experiência do usuário, quando isso não ocorre, o consumidor encontrará dificuldades para finalizar uma compra. Oliveira[19] fala que na atualidade, com o crescimento do Comércio Eletrônico, é indispensável que as organizações deixem de conhecer o processo de decisão de compra através da Internet. Gonçalves[10] complementa dizendo que o processo de consumo dos e-consumidores é um item fundamental para elaboração de um E-Commerce de qualidade. Outros fatores que também devem ser considerados na elaboração do Comércio Eletrônico e que fazem parte da avaliação dos autores, Fell, Rodrigues e Vieira[21] são: consistência, feedback, metáforas, minimização de carga de memória, eficiência no diálogo, exibição exclusiva de informação relevante, uso de rótulos, abreviações e mensagens claras, mecanismo de ajuda, prevenção de erros e tratamento de erros.

Costa[6] realiza um estudo sobre o comportamento de consumidores de nível superior que realizam compras pela Internet. Já Miranda[17] estuda as variáveis comportamentais determinantes na decisão de compra nas relações virtuais entre usuários da Internet integrando os princípios de comportamento do consumidor. Em ambos os trabalhos, a comodidade apresenta-se em destaque como fator de escolha da Internet para efetuar a compra. Em contrapartida, a insegurança juntamente com a falta de contato com o produto são fatores que levam o consumidor a não escolher este meio para finalizá-la. Costa[6] apresenta também que a maioria dos compradores virtuais planeja ou sempre planejam suas compras e que $75,5 \%$ dos entrevistados levam a apresentação do site como critério na hora da escolha. E Gonçalves[10] completa está informação dizendo que "Forma, conteúdo e comportamento devem integrar-se, de maneira que o resultado final permita ao usuário utilizar as ferramentas disponíveis com consistência e facilidade".

Migliorini[16] destaca que a falta de usabilidade implica na rejeição da Internet móvel. Gonçalves[10] em seu trabalho, desenvolveu um aplicativo, baseando-se em estudos feitos através da plataforma desktop do E-Commerce, somente desta forma foi possível perceber o que seria usado e o que seria ocultado na plataforma de $M$-commerce. O mesmo demonstra a importância do profissional de design que será o responsável por apresentar um layout agradável, focado na experiência do usuário, que facilita na hora da compra.

Ainda segundo Migliorini[16], a lentidão causada no carregamento das páginas, dificuldade de navegação e a inacessibilidade de alguns sites, são outros fatores que impendem o usuário de uma navegação agradável pelo celular. Estes itens decorrem dos mesmos estudados por Fell, Rodrigues e Vieira[21], que seriam: consistência e feedback.

Em seu trabalho, Oliveira[19] aborda o comportamento de consumidores de livros que utilizam a Internet para efetuar uma compra, separando pelas etapas de comportamento do consumidor propostas neste trabalho. De acordo com sua pesquisa, as fontes externas são as mais consultadas, e, in- 
fluenciadoras no início do processo de compra.

A partir dos trabalhos apresentados anteriormente, é possível perceber algumas dificuldades encontradas no Comércio Eletrônico de modo geral, bem como alguns fatores que influenciam no processo de compra. No que se refere às plataformas $M$-commerce e E-Commerce, nenhum dos autores acima realizou uma comparação entre estas, mas é importante salientar que todos eles fazem uma abordagem referente à interface da loja virtual, e mostram que a usabilidade, a navegabilidade, o tempo de respostas, a disposição dos elementos na tela, podem influenciar no processo decisório em ambas as plataformas.

\section{METODOLOGIA}

Esta pesquisa tem como objetivo apresentar as características de comportamento do consumidor nas compras realizadas por dispositivos móveis e pelo computador, e, apresentar resultados obtidos por meio de questionários com questões objetivas.

A primeira etapa da pesquisa foi realizada através de um amplo levantamento bibliográfico a fim de especificar as características comportamentais do consumidor virtual. Já a segunda etapa foi definir quais dessas características e fatores comportamentais que deveriam ser comparados entre o $M$-Commerce e E-commerce.

A terceira etapa da pesquisa foi a elaboração do questionário, baseando-se, nos dispositivos que as pessoas utilizam para efetuar uma compra pela Internet, e, dividindo essas pessoas em três grupos: pessoas que só compram pelo computador/notebook, pessoas que só compram pelo celular/tablet, pessoas que compram pelo computador/notebook e pelo celular/tablet.

O método para coleta de dados escolhido foi a aplicação de um questionário, constituído por um total de 16 questões, sendo elas objetivas e do tipo múltipla escolha com uma única resposta e as do tipo matriz, que possui as colunas: Computador/Notebook e Celular/Tablet, de forma que, o usuário, pudesse responder de acordo com as compras realizadas em cada dispositivo. As linhas da matriz representam afirmações e características do processo de compra na Internet.

O questionário foi aplicado de forma online através do link https://pt.surveymonkey.com/s/3TDH6S6, usando o SurveyMonkey, que é um sistema bastante consolidado no mercado para aplicação de questionários online. O link foi compartilhado através de redes sociais, como: Facebook, WatSapp e Linkedin. Não houve restrições quanto a sexo, faixa etária, profissão, sendo o questionário de forma livre para qualquer pessoa apto ou com conhecimento necessário a responder. O questionário poderia ser respondido através de computadores ou celulares com acesso a Internet a qualquer momento.

As perguntas estão divididas em 03 páginas, cada página com o objetivo de coletar hábitos do consumidor na Internet. A primeira página, com um total de 6 perguntas, procura identificar o perfil dos consumidores virtuais e se esses tem hábito de comprar pela Internet. Caso o consumidor respondesse que não, o questionário era encerrado.

Na segunda página, os entrevistados responderam questões do tipo, quais produtos/ serviços que são comprados/ contratados pela Internet e qual o motivo que os leva a desistir de uma compra na Internet.

E por último, a terceira página tem como objetivo, identificar o comportamento do consumidor no processo de com- pra, nos dispositivos móveis e nos computadores. Essa página possui questões sobre a quantidade de produtos, valor das compras, segurança, forma de pagamento e uma comparação direta entre os dois dispositivos.

A seguir será apresentada a análise estática dos dados e serão apresentados os resultados.

\section{RESULTADOS}

Os resultados obtidos na pesquisa são apresentados, seguindo a ordem do questionário, e, com objetivo de apresentar resultados mais consistentes foi aplicado o relacionamento entre algumas respostas.

A análise dos dados foi realizada com base nas respostas de 163 questionados através da plataforma Survey Monkey, durante um período de 30 dias.

Na primeira parte do questionário foi possível identificar o perfil dos consumidores online, tais como: faixa etária, sexo, grau de escolaridade, renda familiar. Dentre esses prevaleceram: Homens (65\%), idade entre 18 e 24 anos $(47,2 \%)$, com nível superior incompleto $(62,6 \%)$, e, seguindo o critério adotado pela Associação Brasileira de Empresas de Pesquisa (ABEP), em setembro de 2014, a classe social que prevaleceu na pesquisa foi a B1 $(41,1 \%)$, que possui renda familiar entre $\mathrm{R} \$ 3.119,00$ até $\mathrm{R} \$ 6.006,00$.

Os resultados mostram também, que a maioria das pessoas possui tanto celular quanto computador com acesso à Internet (92,6\%), e desses, a maioria tem hábito de comprar pela Internet $(89,6 \%)$, como mostra a Tabela 01 .

Tabela 1: Hábito de comprar pela Internet

Tabela 1: Hábito de comprar pela Internet
\begin{tabular}{|l|l|l|}
\hline Você tem o hábito de comprar pela Internet? \\
\hline Opções de Resposta & Porcentagem & Contagem \\
\hline Sim & $89,6 \%$ & 146 \\
\hline Não & $10,4 \%$ & 17 \\
\hline Pessoas que responderam & 163 \\
\hline Pessoas que não responderam & 0 \\
\hline
\end{tabular}

Na segunda parte tem início a comparação entre o processo de compra realizado pelo $E$-Commerce e pelo $M$-Commerce, e, apresenta também, o resultado da categoria de produtos e serviços que mais são comprados nas duas plataformas.

A tabela 2 mostra as 3 categorias de produtos que foram mais selecionadas em cada dispositivo. É importante ressaltar que a questão permitia mais de uma resposta.

Tabela 2: Categorias de Produtos Compradas
\begin{tabular}{|l|l|l|l|l|l|}
\hline \multicolumn{3}{|c|}{$\begin{array}{c}\text { Computador } \\
\text { Notebook }\end{array}$} & \multicolumn{3}{c|}{$\begin{array}{c}\text { Celular } \backslash \\
\text { Tablet }\end{array}$} \\
\hline Categoria & $\begin{array}{l}\text { Quantidade } \\
\text { de Respostas }\end{array}$ & $\%$ & Categoria & $\begin{array}{l}\text { Quantidade } \\
\text { de Respostas }\end{array}$ & $\%$ \\
\hline $\begin{array}{l}\text { Eletrônicos e } \\
\text { Eletrodomésticos }\end{array}$ & 110 & $82,71 \%$ & $\begin{array}{l}\text { Artigos de } \\
\text { Informática }\end{array}$ & 19 & $14,29 \%$ \\
\hline $\begin{array}{l}\text { Artigos de } \\
\text { Informática }\end{array}$ & 93 & $69,92 \%$ & $\begin{array}{l}\text { Livros e } \\
\text { Revistas }\end{array}$ & 15 & $11,28 \%$ \\
\hline Vestuário & 68 & $51,13 \%$ & Games & 15 & $11,28 \%$ \\
\hline
\end{tabular}

É possível perceber com os resultados apresentados acima que os produtos comprados pelo computador são diferentes dos produtos comprados pelo celular, tendo em comum somente Artigos de Informática, mas em proporções bem menores. Outro fator de destaque é que a categoria de produtos mais comprados pelo computador (Eletrônicos e Eletrodomésticos $(82,71 \%)$ ), não aparece entre as três categorias mais selecionadas nas compras pelo celular, já que esta foi escolhida somente por $10,53 \%$ dos consumidores.

O mesmo acontece na contratação de serviços pela Internet, onde pelo computador a maioria dos consumidores con- 
trata serviços de Download de Filmes $(61,83 \%)$ e Compram ingressos $(56,49 \%)$. E pelo celular destaque-se a contratação de serviços de Telefonia e Internet $(25,95 \%)$ e Download de Músicas $(23,66 \%)$, ou seja, os serviços contratados pelo celular são de, preferência, aqueles onde a pessoa pode utilizar no próprio aparelho.

A terceira parte do questionário apresenta resultados sobre o comportamento do consumidor no processo de compra, e, as tabelas 3 e 4 apresentam um relacionamento das questões sobre a quantidade de produtos comprados, o valor gastos nas compras e a forma de pagamento em cada um dos dispositivos.

Tabela 3: Dados Referentes a Última Compra Rea-
lizada no E-Commerce
\begin{tabular}{|l|l|l|l|l|l|}
\hline \multicolumn{5}{|c|}{ Computador/Notebook } \\
\hline $\begin{array}{l}\text { Qnt. } \\
\text { de } \\
\text { Produtos }\end{array}$ & $\%$ & $\begin{array}{l}\text { Valor } \\
\text { gasto nas } \\
\text { compras }\end{array}$ & $\%$ & $\begin{array}{l}\text { Forma } \\
\text { de } \\
\text { pgto }\end{array}$ & $\%$ \\
\hline 2 & $26,77 \%$ & $\begin{array}{l}\text { De } \\
\text { R } \$ 101,00 \\
\text { até } \\
\mathrm{R} \$ 300,00\end{array}$ & $28,13 \%$ & $\begin{array}{l}\text { Cartão } \\
\text { Crédito }\end{array}$ & $84,13 \%$ \\
\hline 1 & $25,98 \%$ & $\begin{array}{l}\text { De } \$ 301,00 \\
\text { até } \\
\mathrm{R} \$ 500,00\end{array}$ & $16,41 \%$ & Boleto & $34,92 \%$ \\
\hline 3 & $20,47 \%$ & $\begin{array}{l}\mathrm{De} \\
\mathrm{R} \$ 51,00 \\
\text { até } \\
\mathrm{R} \$ 100,00\end{array}$ & $10,94 \%$ & $\begin{array}{l}\text { Pag } \\
\text { Seguro }\end{array}$ & $18,25 \%$ \\
\hline
\end{tabular}

Tabela 4: Dados Referentes a Última Compra Rea-
lizada no M-Commerce
\begin{tabular}{|l|l|l|l|l|l|}
\hline \multicolumn{5}{|c|}{ Celular/Smarphone } \\
\hline $\begin{array}{l}\text { Qnt. } \\
\text { de } \\
\text { Produtos }\end{array}$ & $\%$ & $\begin{array}{l}\text { Valor } \\
\text { gasto nas } \\
\text { compras }\end{array}$ & $\%$ & $\begin{array}{l}\text { Forma } \\
\text { de } \\
\text { pgto. }\end{array}$ & $\%$ \\
\hline 1 & $15,75 \%$ & $\begin{array}{l}\text { De } \\
\text { R } \$ 10,00 \\
\text { até } \\
\mathrm{R} \$ 50,00\end{array}$ & $9,38 \%$ & $\begin{array}{l}\text { Cartão } \\
\text { Crédito }\end{array}$ & $31,75 \%$ \\
\hline \multirow{2}{*}{$\begin{array}{l}\text { De } \\
\mathrm{R} \$ 101,00 \\
\text { até } \\
\mathrm{R} \$ 300,00\end{array}$} & $7,03 \%$ & Boleto & $7,14 \%$ \\
\hline 3 & $6,30 \%$ & $\begin{array}{l}\text { De } \\
\mathrm{R} \$ 301,00 \\
\text { até } \\
\mathrm{R} \$ 500,00\end{array}$ & $5,47 \%$ & PayPal & $7,14 \%$ \\
\hline
\end{tabular}

Como dito anteriormente os consumidores do $M$-Commerce preferem comprar produtos ou serviços que podem ser utilizados no próprio dispositivo móvel. Na Tabela 4 é possível concluir que esses consumidores compram na maioria das vezes apenas 1 produto/serviço de baixo valor, e, relacionando esse resultado com as categorias selecionadas, frequentemente essas compras são de aplicativos para o próprio celular ou produtos de valor baixo como livros e revistas.

A preferência pelo pagamento através do cartão de crédito ainda é unânime pelos consumidores dos dois dispositivos. Esse é o meio de pagamento mais atraente para estes, pois, podem parcelar suas compras, principalmente quando o valor é alto. As compras realizadas pelo cartão de crédito também proporcionam mais segurança por causa da entrega do produto, que pode chegar danificado, não atender as expectativas ou até mesmo nem ser entregue. Com isso o consumidor se resguarda de não pagar o produto logo de uma vez.

Outro aspecto identificado no comportamento do consumidor é em relação ao processo de pesquisa de produtos na Internet, onde o resultados da tabela 5 e 6 demonstram que os consumidores pesquisam muito, antes de tomar a decisão sobre a compra, tanto no computador quanto nas compras pelo celular.

Tabela 5: Pesquisa do Consumidor no E-Commerce
\begin{tabular}{|l|l|}
\hline \multicolumn{2}{|c|}{ Computador/Notebook } \\
\hline $\begin{array}{l}\text { Quantidade de sites visitados antes de efetuar } \\
\text { a compra. }\end{array}$ \\
\hline Mais que 5 & $38,58 \%$ \\
\hline 3 & $29,92 \%$ \\
\hline 4 & $16,54 \%$ \\
\hline
\end{tabular}

Tabela 6: Pesquisa do Consumidor no M-Commerce
\begin{tabular}{|l|l|}
\hline \multicolumn{2}{|c|}{ Celular/Tablet } \\
\hline $\begin{array}{l}\text { Quantidade de sites visitados antes de efetuar } \\
\text { a compra. }\end{array}$ \\
\hline Mais que 5 & $18,90 \%$ \\
\hline 3 & $11,81 \%$ \\
\hline 2 & $7,87 \%$ \\
\hline
\end{tabular}

Atualmente os dois dispositivos permitem que o consumidor consulte com facilidade varias lojas virtuais, e, com auxílio de ferramentas de busca como: Buscapé, Zoom e BondFaro proporcionam mais praticidade na hora da pesquisa.

Ainda com relação ao processo de pesquisa, os dados das tabelas 7 e 8 mostram que os consumidores do E-Commerce e do $M$-Commerce desistem de uma compra na Internet mais por motivos financeiros e pelo fato de não encontrarem o produto que buscam no site. Além disso, é possível afirmar que os consumidores do $M$-Commerce também se preocupam com erros inesperados que aparecem na pesquisa e dificuldades de navegação. Por se tratar de uma interface menor, onde o consumidor tem o contato diretamente com na tela do aparelho, os compradores do mobile commerce são mais impacientes a erros não tratados, ou quando o programa é encerrado de forma inesperada.

Tabela 7: Motivos pelo Qual o Consumidor Desiste de uma Compra no E-Commerce

\begin{tabular}{|l|l|}
\hline \multicolumn{2}{|c|}{ Computador/Notebook } \\
\hline Motivos que levam consumidor a desistir da compra \\
\hline Quando o valor do frete é alto & $79,55 \%$ \\
\hline $\begin{array}{l}\text { Quando o preço está mais alto que na } \\
\text { loja física }\end{array}$ & $78,03 \%$ \\
\hline Quando não encontro os produtos que desejo & $73,48 \%$ \\
\hline
\end{tabular}

Tabela 8: Motivos pelo Qual o Consumidor Desiste de uma Compra no $M$-Commerce

\begin{tabular}{|l|l|}
\hline \multicolumn{2}{|c|}{ Celular/Tablet } \\
\hline Motivos que levam consumidor a desistir da compra \\
\hline $\begin{array}{l}\text { Quando não encontro } \\
\text { os produtos que desejo }\end{array}$ & $40,15 \%$ \\
\hline $\begin{array}{l}\text { Quando o preço está } \\
\text { mais alto que na loja física }\end{array}$ & $33,78 \%$ \\
\hline $\begin{array}{l}\text { Quando ocorre um erro } \\
\text { inesperado }\end{array}$ & $37,12 \%$ \\
\hline
\end{tabular}

Até o momento é possível perceber algumas diferenças no perfil dos consumidores em relação às compras realizadas pela Internet, como, tipo produtos/serviços comprados, valor gasto nas compras, formas de pagamento e motivos que levam estes a desistirem de uma compra. Neste ponto, é possível perceber que os consumidores estão sujeitos a mudança de comportamento de acordo com o dispositivo em 
que está efetuando a compra. No entanto a tabela 9 mostra um resultado que compara a utilização dos dispositivos (computador e celular) durante o processo de compra online.

Tabela 9: Processo de Compra na Internet Atividades realizadas no processo de compra online de acordo com cada dispositivo

\begin{tabular}{|l|l|l|}
\hline & $\begin{array}{l}\text { Computador } \\
\text { /Notebook }\end{array}$ & $\begin{array}{l}\text { Celular } \\
/ \text { Tablet }\end{array}$ \\
\hline $\begin{array}{l}\text { Visito sites em busca de promoções de } \\
\text { produtos e serviços }\end{array}$ & $79,69 \%$ & $32,03 \%$ \\
\hline Faço cadastro para comprar no site & $82,81 \%$ & $25,00 \%$ \\
\hline $\begin{array}{l}\text { Utilizo o chat para falar com } \\
\text { vendedor }\end{array}$ & $30,47 \%$ & $5,47 \%$ \\
\hline $\begin{array}{l}\text { Visualizo comentários } \\
\text { de outros compradores }\end{array}$ & $83,33 \%$ & $31,06 \%$ \\
\hline $\begin{array}{l}\text { Visualizo as características } \\
\text { do produto }\end{array}$ & $88,28 \%$ & $35,94 \%$ \\
\hline $\begin{array}{l}\text { Adiciono produtos } \\
\text { ao carrinho de compra }\end{array}$ & $83,59 \%$ & $26,56 \%$ \\
\hline $\begin{array}{l}\text { Seleciono a forma de } \\
\text { pagamento }\end{array}$ & $88,28 \%$ & $25,78 \%$ \\
\hline Efetuo o pagamento & $88,28 \%$ & $26,56 \%$ \\
\hline $\begin{array}{l}\text { Faço Acompanhamento } \\
\text { do Pedido }\end{array}$ & $86,72 \%$ & $33,59 \%$ \\
\hline $\begin{array}{l}\text { Faço um comentário } \\
\text { ou avaliação do Produto }\end{array}$ & $37,50 \%$ & $14,84 \%$ \\
\hline
\end{tabular}

De acordo com a tabela anterior é possível perceber a fragilidade do $M$-Commerce com relação às vendas realizadas pela Internet, pois, todas as atividades são realizadas mais no computador do que no celular. Entretanto, é importante ressaltar que as atividades que são mais executadas no celular são as de pesquisa e visualização dos produtos e acompanhamento do pedido. Esse fato é justificado pelo uso do celular no dia a dia das pessoas, onde a possibilidade de acesso à Internet de qualquer lugar proporciona essa comodidade para que os consumidores com tempo livre busquem produtos e promoções na Internet e possam acompanhar o pedido caso já tenha efetuado a compra.

A tabela 10 exibe os motivos pelo qual os consumidores virtuais ainda preferem mais efetuar a compra pelo computador do que pelo celular.

Tabela 10: Motivos que Influenciam o Consumidor na Escolha de cada Dispositvo

\begin{tabular}{|l|l|l|}
\hline \multicolumn{3}{|l|}{$\begin{array}{l}\text { Atividades realizadas no processo de compra } \\
\text { online de acordo com cada dispositivo }\end{array}$} \\
\hline & $\begin{array}{l}\text { Computador } \\
/ \text { Notebook }\end{array}$ & $\begin{array}{l}\text { Celular } \\
/ \text { Tablet }\end{array}$ \\
\hline $\begin{array}{l}\text { Tenho mais habilidade } \\
\text { para efetuar a compra }\end{array}$ & $86,72 \%$ & $3,13 \%$ \\
\hline $\begin{array}{l}\text { Tenho mais segurança } \\
\text { para efetuar a compra }\end{array}$ & $81,25 \%$ & $5,47 \%$ \\
\hline $\begin{array}{l}\text { Tenho mais comodidade } \\
\text { para efetuar a compra }\end{array}$ & $68,75 \%$ & $24,22 \%$ \\
\hline $\begin{array}{l}\text { Utilizo mais para pesquisar } \\
\text { ofertas na Internet }\end{array}$ & $55,47 \%$ & $34,38 \%$ \\
\hline $\begin{array}{l}\text { Utilizo mais para comparar } \\
\text { preços na Internet }\end{array}$ & $67,97 \%$ & $21,88 \%$ \\
\hline $\begin{array}{l}\text { Utilizo mais durante o dia } \\
\text { para navegar } \\
\text { na Internet/rede social }\end{array}$ & $22,66 \%$ & $65,63 \%$ \\
\hline
\end{tabular}

Como falado anteriormente, o uso do celular no dia a dia das pessoas está maior do que a utilização de computadores, entretanto as compras ainda continuam maiores no computador por motivos de segurança $(81,25 \%)$ e mais habilidade $(86,72 \%)$ para conseguir efetuar a compra.
A segurança é um grande problema enfrentado nas compras pela Internet, e, muito mais no $M$-Commerce. Os consumidores se preocupam ao fornecerem dados pessoais e efetuarem pagamento, pois, não sabem se de fato esses serão mantido em segurança. Baseando-se nisso, existem algumas formas do consumidor conseguir se proteger ao efetuar uma compra na Internet, que será visto na tabela 11.

Tabela 11: Segurança nas Compras Online

\begin{tabular}{|c|c|c|}
\hline \multicolumn{3}{|c|}{$\begin{array}{l}\text { Cuidados que consumidores tem } \\
\text { nas compras online de acordo com cada } \\
\text { dispositivo }\end{array}$} \\
\hline & $\begin{array}{l}\text { Computador } \\
\text { /Notebook }\end{array}$ & $\begin{array}{l}\text { Celular } \\
\text { /Tablet }\end{array}$ \\
\hline $\begin{array}{l}\text { Compro somente em sites } \\
\text { que possui certificados } \\
\text { de segurança }\end{array}$ & $83,72 \%$ & $27,91 \%$ \\
\hline Possuo antivírus instalado & $66,67 \%$ & $17,05 \%$ \\
\hline $\begin{array}{l}\text { Sempre me conecto em uma } \\
\text { rede segura para } \\
\text { realizar a compra }\end{array}$ & $64,34 \%$ & $18,60 \%$ \\
\hline $\begin{array}{l}\text { Recebo mensagens/e-mails } \\
\text { informando sobre dados } \\
\text { de pagamento }\end{array}$ & $79,84 \%$ & $31,78 \%$ \\
\hline $\begin{array}{l}\text { Já tive dados roubados/ } \\
\text { alterados e usados por } \\
\text { terceiros }\end{array}$ & $5,43 \%$ & $1,55 \%$ \\
\hline
\end{tabular}

Os consumidores se preocupam na hora da compra, se o site é seguro, entretanto muitos se conectam em redes abertas o que é um descuido, já que, em uma rede aberta também é possível que os dados sejam roubados. Para o celulares o risco é maior já que este dispositivo é mais propício a roubo e os consumidores não se preocupam tanto a segurança, já que poucas pessoas possuem antivírus instalado e na maioria das vezes estão conectados a redes abertas.

\section{CONCLUSÕES}

O M-Commerce vem aumentando sua porcentagem de vendas a cada ano e o número de pessoas que se conectam a Internet através de dispositivos móveis supera as expectativas do mercado. As previsões são de que os números aumentem nos próximos anos.

Esta pesquisa apresenta o comportamento do consumidor no processo de compra pela Internet nos dispositivos móveis e nos computadores, o perfil dos consumidores, os hábitos e expõe dados sobre o mercado brasileiro de Comércio Eletrônico. Mostra também que as pessoas utilizam mais os dispositivos móveis durante dia $(65,63 \%)$, entretanto, quando necessitam realizar uma compra na Internet preferem efetuar a compra no computador. E importante destacar que todo o processo de compra realizado diretamente no computador, desde a busca pelos produtos até a finalização da compra sendo que os dispositivos móveis apenas auxiliam neste processo, como nas atividades de pesquisar os produtos e para acompanhamento do pedido.

A sociedade está passando por uma mudança cultural, que já havia ocorrido antes com o surgimento do E-Commerce, onde os consumidores foram deixando as compras na loja física e migrando cada vez para a Internet, o mesmo deve acontecer com as compras realizadas através dos smartphones. De acordo com a pesquisa $92,6 \%$ dos entrevistados possui tanto celular quanto computador com acesso à Internet e $89,6 \%$ tem hábito de comprar pela Internet.

Os consumidores estão se adaptando a comprar neste tipo de dispositivo, mas é necessário que as operadoras de tele- 
fonia melhorem sua infraestrutura de rede para uma melhor conexão do consumidor e que as empresas responsáveis pelo desenvolvimento dos sites de $M$-commmerce melhorem as interfaces de modo a proporcionarem uma melhor experiência para usuário, pois $86,72 \%$ dos consumidores possuem mais habilidade para efetuarem a compra pelo computador.

É necessário também que o consumidor se sinta seguro ao efetuar compras no $M$-Commerce, já que $81,25 \%$ dos consumidores dizem ter mais segurança ao efetuarem uma compra no computador e a partir disso os consumidores passariam a consumir produtos com valores mais altos já que o valor gasto em média nas compras pelo celular é de $\mathrm{R} \$ 10,00$ a $\mathrm{R} \$$ 50,00 e de apenas um produto $(15,75 \%)$. Outro problema que também deve ser resolvido é em relação aos erros que ocorrem durante a compra, já que $37,12 \%$ das pessoas desistem da compra quando ocorre um erro inesperado. As redes de varejo necessitam criar campanhas promocionais para atrair o consumidor para comprar pelo smartphone, pois de acordo com $33,78 \%$ dos consumidores de $M$-Commerce que responderam a pesquisa, desistem da compra quando o preço está maior que na loja física.

Apesar do abrangente campo de estudos no que refere a compra pela Internet, uma oportunidade seria explorar o desenvolvimento de interfaces de vendas para dispositivos móveis, de forma a proporcionar mais facilidade na hora da compra. Outra opção de estudo diz respeito melhores estratégias de Marketing de forma a fomentar as vendas através de dispositivos móveis.

\section{REFERÊNCIAS}

[1] F. ALEXANDRINI. Perfil empresarial na prática do e-commerce: comercialização eletrónica. Universidade Federal de Santa Catarina, Centro Tecnológico. Programa de Pós-Graduação em Engenharia de Produção., 2000.

[2] C. ANGELO and J. SILVEIRA. Varejo Competitivo. Editora Atlas, 3th edition, 1999.

[3] C. ANGELO and J. SILVEIRA. Varejo Competitivo. Editora Atlas, 6th edition, 2001.

[4] R. BLACKWELL, P. MINIARD, and J. ENGEL. Comportamento do Consumidor. Editora Thomson Pioneira, 9th edition, 2005.

[5] R. CARVALHO. Negócios Eletrônicos na modalidade B2C - Business to Consumer - Um estudo de caso de uma empresa varejista de produtos eletroeletrônicos em Fortaleza, 2010. Monografia (Bacharel Ciência da Computação) - FLF (Faculdade Lourenço Filho Ciência da Computação), Fortaleza, Brasil.

[6] F. COSTA. Comércio Eletrônico: Hábitos do Consumidor na Internet, 2009. Dissertação (Mestrado Profissional em Administração) - FPL (Fundação Pedro Leopoldo), Pedro Leopoldo, Brasil.

[7] H. DEITEL, P. J. DEITEL, and K. STEINBUHLER. E-business e e-commerce para administradores. Pearson Education, 2004.

[8] E-BIT. Comércio eletrônico no brasil. http://www.ebit.com.br/webshoppers, 2013. Último Acesso em: 07-03-2014.

[9] J. ENGEL, R. BLACKWELL, and P. MINIARD. Comportamento do Consumidor. LTC Editora, 8th edition, 2000.

[10] F. GONÇALVES. M-Commerce: Projetando o
Processo de Compra para Smartphones, 2013. Monografia (Bacharel Design Digital) - UFPEL (Universidade Federal de Pelotas), Pelotas, Brasil.

[11] HI-MIDIA. E-commerce: Comportamento dos e-consumidores.

http://www.hi-midia.com/pesquisas/maio2012-ecommerce-comportamento-dos-e-consumidores/, 2012. Último Acesso em: 18-03-2014.

[12] HI-MIDIA. Mercado de mobile e de m-commerce no brasil. http://www.hi-midia.com/pesquisas/outubro2012-pesquisa-analisa-o-mercado-de-mobile-e-de-mcommerce-no-brasil, 2012. Último Acesso em: 07-03-2014.

[13] P. KOTLER and K. L. KELLER. Administração de Marketing. Pearson Prentice Hall, 12th edition, 2006.

[14] S. MARTI. Mobile commerce não é tendência, é um fato atual.

http://www.ecommercebrasil.com.br/artigos/mobilecommerce-nao-e-tendencia-e-um-fato-atual, 2014. Último Acesso em: 18-03-2014.

[15] F. MARTINS. 4 cuidados para não perder clientes virtuais.

http://ecommercenews.com.br/artigos/tutoriais/4cuidados-para-nao-perder-clientes-virtuais, 2012. Último Acesso em: 16-03-2014.

[16] A. MIGLIORINI. Mobile Commerce - E-commerce, 2009. Trabalho de curso (Bacharelado em Administração) - UNIVEM (Centro Universitário Eurípides de Marília), Marília, Brasil.

[17] C. MIRANDA and D. ARRUDA. E-produtos e variáveis comportamentais determinantes de ccompra no varejo virtual: Um estudo com consumidores brasileiros. REAd, 10(1), 2004.

[18] J. O'BRIEN. Sistemas de Informação e as Decisões Gerenciais na Era da Internet. Saraiva, 2004.

[19] E. OLIVEIRA. Comportamento do consumidor processo de decisão de compra de livros pela internet, 2007. Dissertação (Mestrado Profissional em Administração) - USP (Universidade de São Paulo), São Paulo, Brasil.

[20] O. M. Planet. Nosso planeta mobile: Brasil - como entender o usuário de celular. http://services.google.com/fh/files/misc/omp-2013-brlocal.pdf, 2013. Último Acesso em: 28-03-2014.

[21] G. RODRIGUES, A. VIEIRA, and A. FELL. Avaliação de experiência de compra no e-commerce a partir da taxonomia da usabilidade. Encontro de Estudos Sobre Tecnologia, Ciência e Gestão da Informação, 2013.

[22] K. SILVA, R. PRADO, M. SILVA, and J. SILVA. Processo de decisão de compra: Um estudo sobre o comportamento do consumidor virtual. XXXIII Encontro Nacional de Engenharia de Produção, 2013.

[23] TELEBRASIL. Número de acessos em banda larga chega a 137 milhões.

http://www.telebrasil.org.br/sala-deimprensa/releases/5490-numero-de-acessos-em-bandalarga-chega-a-137-milhoes-em-janeiro, 2013. Último Acesso em: 07-03-2014. 